\title{
Are you allergic to
}
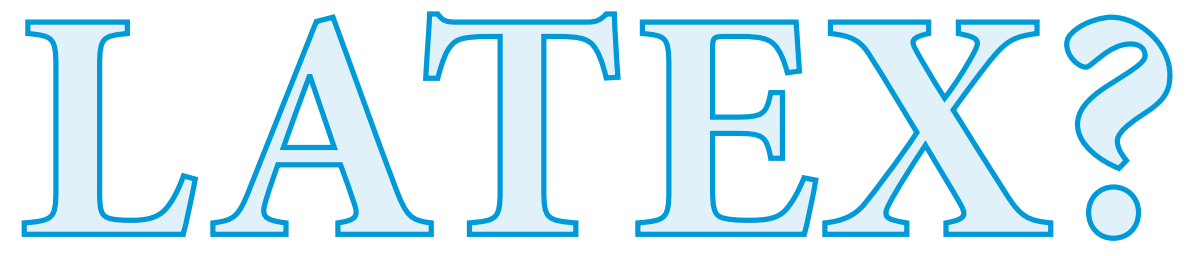

\section{Edward Sinclair ${ }^{1}$ discusses hand dermatitis and latex allergy among dental workers.}

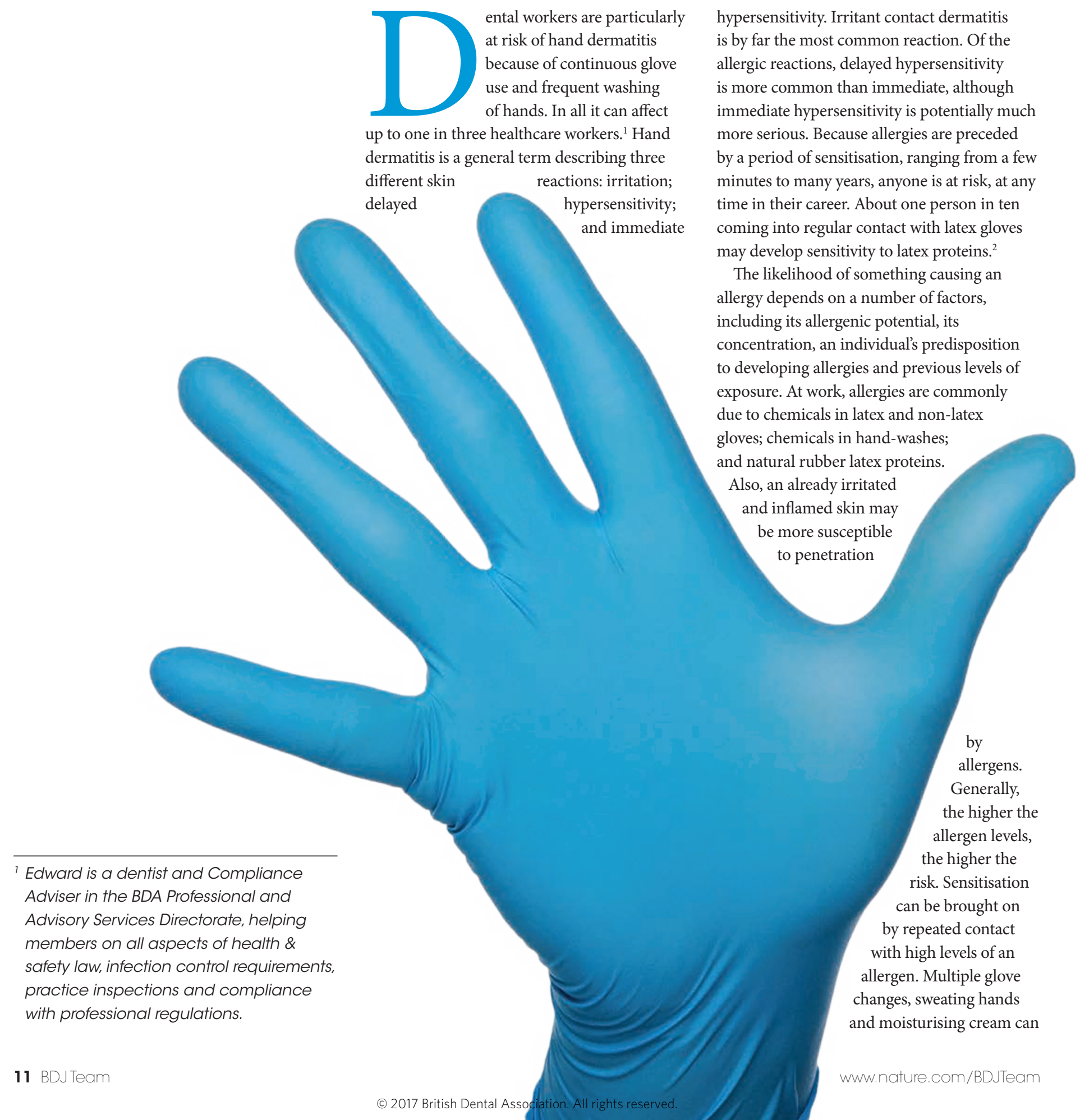


liberate latex proteins increasing risk of allergy due to cutaneous exposure. However, once allergic, someone may experience reactions at much lower levels.

\section{Seek help}

If you suspect hand dermatitis or latex allergy seek medical advice from your medical practitioner, local occupational health expert or dermatologist. This is particularly important if you think you may have become sensitised to latex. Latex allergy can be potentially life-threatening and expert advice must be sought immediately.

Management usually depends on the cause and severity, and medical advice is required to confirm a diagnosis and decide the best way to manage the problem. Various tests can be used to determine whether dermatitis is allergy-based. Failure to identify an allergen may then mean looking at potential skin irritants for the cause.

\section{Risk assessment}

Latex allergy and contact dermatitis should be included in your practice COSHH risk assessments. There is no need to have a separate policy on latex allergy as long as you have carried out a proper assessment that identifies exposure to latex and ways in which exposure can be prevented or controlled.

Practices should not scrimp on glove quality. Lower quality gloves are more likely to cause allergy. Gloves should have the lowest levels possible of chemical accelerators; if latex is

worn the

levels of extractable proteins should be $<50 \mu / \mathrm{g}$.

However, it is imperative that there is a non-latex alternative in terms of gloves available to staff that can be used whenever

\section{'MULTIPLE GLOVE CHANGES, SWEATING HANDS}

AND MOISTURISING CREAM CAN LIBERATE

\section{LATEX PROTEINS INCREASING RISK}

required. Potential alternatives include nitrile and neoprene. Practice managers should ensure that those ordering stock are aware of the types of gloves to be ordered. In addition, staff should be trained not only in identifying latex allergy risks but how to deal with anaphylaxis in an emergency.

Many other latex containing products are used in the dental surgery; this includes

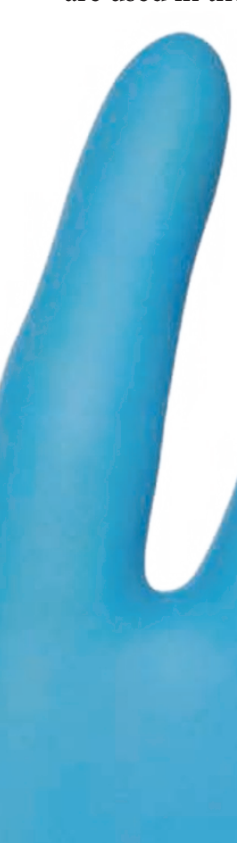

rubber dams. A

non-latex alternative should

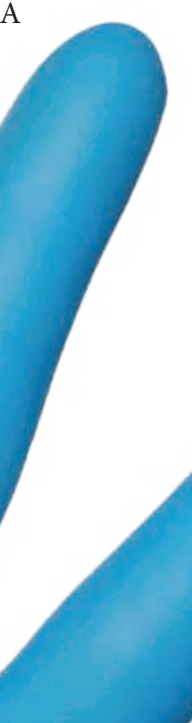

diaphragms and plungers can also contain latex. However, given the lack of evidence, it is difficult to directly attribute this particular source of latex to allergies within the dental surgery.

In theory, there could also be some cross reactivity with gutta percha material. Again, this is only theoretical given both materials have common sources. There is no evidence in the literature to substantiate such a comparison. In patients known to have a latex allergy, it may be prudent to allergy test for gutta percha sensitivity.

With your patients around 1-6\% of the general population are thought to be potentially sensitised to latex.

Control measures to prevent allergy to latex include taking an excellent medical history, considering co-morbidities that may increase the risk of latex allergy and the use of barrier protection from contact with latex containing materials. It has been suggested that early morning appointments could be helpful in preventing patient exposure to allergens that have become

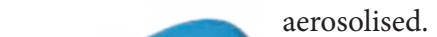
Full national guidelines Latex allergy-Occupational aspects of management, are published by the Royal College of Physicians; visit https:// www.rcplondon.ac.uk/guidelinespolicy/latex-allergy-occupational-aspectsmanagement-2008.

be used in these situations, whenever possible. Contrary to some reports, the risk of latex allergies from local anaesthetic carriages is minimal. Some have been manufactured with latex
1. Flyvholm M A, Bach B, Rose M, Jepsen K F. Self-reported hand eczema in a hospital population. Contact Dermatitis 2007; 57: 110-115.

2. Allergy UK. Rubber Latex Allergy. Available at: https://www.allergyuk.org/ rubber-latex-allergy/rubber-latex-allergy (accessed February 2017).

bdjteam 201741 